\title{
PETER SLOTERDIJK: "LA VIDA DEBIERA ORIENTARSE MENOS HACIA SU PROLONGACIÓN Y MÁS HACIA SU PROFUNDIDAD”*
}

\author{
Alfonso Peró \\ El Mercurio
}

\begin{abstract}
Resumen: En esta entrevista, previa a su visita a Chile en noviembre de 2018, el filósofo alemán Peter Sloterdijk se refiere a distintos tópicos de su obra filosófica, tales como la administración política de la ira, la voluntariedad de los impuestos y la globalización. También aborda otros temas coyunturales, como el auge del populismo y la crisis de la Iglesia Católica.

PALABRAs Clave: ira, impuestos, populismo, globalización.
\end{abstract}

Peter SloterdiJK. Filósofo alemán (Karlruhe, 1947). Autor de Crítica de la razón cínica (1983) y Esferas I, II y III (1998, 1999 y 2004), así como de los ensayos Ira y tiempo (2006), Los hijos terribles de la modernidad (2014), ¿Qué sucedió en el siglo $X X$ ? (2016), entre otros libros.

Alfonso Peró. Periodista de la Universidad Finis Terrae. Management and Business Track Diploma Program UC Berkeley y Eisenhower Fellow. Editor de política y reportajes de El Mercurio. Email: alfonso.pero@mercurio.cl.

* Versión revisada de la entrevista hecha por Peró a Sloterdijk vía email y publicada en el cuerpo Reportajes de El Mercurio, el domingo 11 de noviembre de 2018. Estudios Públicos agradece a Enrique Barros Bourie la traducción de esta entrevista. La versión en alemán se reproduce para quienes quieran acceder a las respuestas originales de Sloterdijk. 


\section{PETER SLOTERDIJK: \\ "WE SHOULD BE CONCERNED LESS WITH THE LENGTH OF LIFE THAN WITH ITS DEPTH"}

AвSTRACT: In this interview before his visit to Chile in November 2018, the German philosopher Peter Sloterdijk talks about different areas of his philosophical work, such as the political administration of rage, voluntary taxation and globalization. He also addresses other topical issues such as the rise of populism and the crisis in the Catholic Church.

KEYwORDS: rage, taxation, populism, globalization.

\section{INTRODUCCIÓN}

O i bien las respuestas que da son atractivas y provocativas - una - rara mezcla de imágenes difusas y concretas - , las preguntas que plantea el filósofo alemán Peter Sloterdijk (1947) son fuertemente resonantes, impregnadas todas de vínculos amplios: ¿Cómo se racionaliza el Estado? ¿Cómo conciliar el hecho de que mientras la economía necesita la paz, el Estado necesita la guerra? ¿Quiénes cumplen hoy con el papel de administrar la ira? Es un rupturista, le dicen el Friedrich Nietzsche de nuestra época. Impregna frases como "hoy el ciudadano, el individuo moderno, acumula desilusiones", 1 tras declarar que hay que repensar el Estado, pues la ciudadanía demanda autenticidad y paz ("la utopía de hoy es un Estado libre de guerras"2), mientras que el Estado es una "potencia bélica" que observa al individuo como un deudor y no como un contribuyente generoso. A su juicio, la tensión entre el Estado y la libertad — pues el primero habría surgido de los gobiernos absolutistasmonopoliza el poder por el miedo. ${ }^{3}$

El mayor problema que ve en esto es que se acumula la ira y "la ira se convierte en resentimiento; aquí volvemos a Nietzsche, porque Nietzsche es el padre fundador de la filosofía del resentimiento. Los

${ }^{1}$ Tomado de Sloterdijk en Chile, "El Estado y el futuro de la sociedad", segunda conversación del filósofo, realizada con Sylvia Eyzaguirre y Leonidas Montes el martes 13 de noviembre de 2018, en el Centro de Estudios Públicos. Disponible en https://www.youtube.com/watch?v=wnfZHnAKh18.

2 Ibídem.

${ }^{3}$ Ibídem. 
afectos como la ira y otros pueden ser recolectados en bancos de afectos, y los partidos políticos son esos bancos de afectos, que pueden aclarar mi ira de manera de que mis afectos lleguen a representarse en el escenario social". ${ }^{4}$

Por otro lado, para el filósofo, la tributación actual tiene un fundamento inadecuado, que otorga un poder muy amplio al Estado y que perjudica a los contribuyentes, de manera que debe pensarse una nueva ética política para el futuro. Dice: "Excluir a la ciudadanía de las grandes decisiones alimenta un proceso de degeneración del modelo democrático y se corre el riesgo de una indignación general". 5

Según Sloterdijk, aún no peligra la democracia, pero "el sistema está muy debilitado. Los electores sienten que no hay alternativas y que todo conduce a la confusión". 6 "No creo que la sociedad occidental esté en vísperas de una erupción volcánica en la política (...). Puede ser un choque más que un estallido", ${ }^{7}$ dice con ese tono pausado con el que le da a cada letra un sentido magistral.

\footnotetext{
${ }^{4}$ Ibídem.

${ }^{5}$ Ibídem.

${ }^{6}$ Ibídem.

${ }^{7}$ Ibídem.
} 


\section{INTERVIEW}

-In einem Ihrer Bücher behaupten Sie, dass ,,der Zorn durch enttäuschte Hoffnungen entfacht werden kann ". Heutzutage ist die Gesellschaft durch Gewalt, Unzuverlässigkeit, Arbeitslosigkeit, Korruption usw. geprägt. Glauben Sie, dass das Abendland einem Vulkan gleicht, der jeden Moment ausbrechen kann?

-Mir scheint, wir könnten nichts Besseres tun, als unser Gespräch mit Überlegungen zu Ausdrücken wie Wut, Hoffnung, Enttäuschung und Mißtrauen zu beginnen. Sie gehören zum Vokabular der psychopolitischen Analyse, mit der ich mich seit einem Vierteljahrhundert beschäftige. Ihre Frage zeigt, dass es unter diesen Begriffen eine Reihenfolge gibt, die aus der Logik der politisch wirksamen Gefühle folgt. Wenn man mit Hoffnung und Vertrauen angefangen hat und Enttäuschung erlebt, sind Mißtrauen und Wut die natürlichen Konsequenzen. Diese werden greifbar in Wahlen, bei denen Wutparteien und Koalitionen des Mißtrauens an Macht gewinnen. Phänomene wie Korruption, Gewalt und Arbeitslosigkeit werden, der psychopolitischen Analyse gemäß, in erster Linie als Faktoren der Demoralisierung bzw. der Entmutigung und der Isolierung wirksam. An ihnen ist ja nichts, worauf die Betroffenen gemeinsam stolz sein könnten; bestenfalls lassen sich unter ihnen Abwehrbündnisse gegen die Übel schließen. Nur selten bewirkt die Empörung breitere und haltbare Solidarisierungseffekte.

Ich denke nicht, daß der westlichen Gesellschaft eine Phase des politischen Vulkanismus bevorsteht. Es kann viel passieren, aber für die typischen Veränderungen von heute sind eher Implosionen bezeichnend: Die Sowjetunion verschwand durch Implosion, die sklerotische DDR ging lautlos unter, Venezuela implodierte, das etablierte französische Parteiensystem wurde an einem Wahltag im Juni 2017 durch Macrons Bewegung La république en marche fast lautlos in den Urlaub geschickt. Was Italien angeht, so existiert sein politisches System seit langem in dem paradoxen Zustand der ,permanenten Implosion“. Was sich hingegen explosiv entwickelt, sind die Staatsschulden vieler Länder. Verstehen wir die Vulkanexplosion als Metapher für „Revolution“ -wie in der ersten Strophe der Internationale: c'est l'éruption de la fin-, so wird einem klar, dass es heute mehr um den Crash als um den Ausbruch geht. 


\section{ENTREVISTA}

-En uno de sus libros, usted ha dicho que la ira se puede despertar cuando se decepcionan las esperanzas. ${ }^{8}$ Hoy, las sociedades están marcadas por la violencia, la desconfianza, el desempleo, la corrupción, etcétera. ¿Cree que Occidente es un volcán a punto de explotar?

-Nada mejor que comenzar nuestra conversación con reflexiones sobre conceptos como rabia, esperanza, desengaño y desconfianza. Pertenecen al vocabulario del análisis psicopolítico, al que me he dedicado por un cuarto de siglo. Su pregunta muestra que entre estos conceptos existe una secuencia, que se sigue de la lógica de los sentimientos que son efectivos en la política. Cuando se ha partido de la esperanza y de la confianza y se experimenta el desengaño, las consecuencias naturales son desconfianza y rabia. Éstas son tangibles en las elecciones, en las que ganan el poder partidos de la ira y coaliciones de la desconfianza. Fenómenos como corrupción, violencia y cesantía, según el análisis psicopolítico, son eficaces en primera línea como factores de desmoralización, desánimo y aislamiento. Con estos sentimientos, los afectados no tienen nada de lo que puedan sentirse orgullosos en común; en el mejor de los casos, pueden provocar acuerdos defensivos frente al mal. Sólo muy raramente la rabia puede producir efectos amplios y sustentables de solidaridad.

No creo que la sociedad occidental esté en vísperas de una erupción volcánica en la política. Pueden ocurrir muchas cosas, pero lo característico de estos tiempos son los cambios por implosión, por derrumbe hacia adentro. La Unión Soviética desapareció por implosión. Venezuela se ha derrumbado por implosión. En un día de elecciones, en junio de 2017, el sistema tradicional de partidos en Francia fue enviado de vacaciones sin ruido por La république en marche!, de Macron. En Italia existe por largo tiempo un sistema político en "permanente implosión". Por el contrario, en muchos países lo que sí se desarrolla explosivamente es la deuda pública. Si entendemos la erupción volcánica como metáfora de la "revolución" — como dice la primera estrofa de la Internacional: c'est l'éruption de la fin-, a uno le resulta claro que puede ser un crash, más que de un estallido.

${ }^{8}$ Peter Sloterdijk, Ira y tiempo. Ensayo psicopolítico, traducción de Miguel Ángel Vega Cernuda y Elena Serrano (Madrid: Siruela, 2010). 
-Friedrich Hayek sagte, ein guter Wirtschaftswissenschaftler soll nicht nur Wirtschaftswissenschaftler sein. Hayek selbst dachte wohl, dass er etwas mehr als ein bloßer Wirtschaftswissenschaftler war. In den letzten Jahren überwiegen die Wirtschaftswissenschaftler in der Gestaltung der Politik. Fehlt nicht die politische Philosophie in der Entwicklung der Politik?

-Die Frage, ob es unseren Systemen des Zusammenlebens in Staaten an politischer Philosophie fehlt, ist mit Nein zu beantworten. Fürs erste ist an Philosophie kein Mangel zu erkennen. Alle wesentlichen Spieler auf der Staatenbühne der Welt repräsentieren Verfassungsstaaten - Verfassungen sind nichts anderes als gefrorene politische Philosophien, nicht selten auch politische Anthropologien. Diese bekunden sich in Grundrechts-Katalogen und im Design von Institutionen, in der Regel aufbauend auf aufklärerischen Ideen zur Teilung der exekutiven Gewalt von der rechtsprechenden und der gesetzgebenden. Auf dem Papier ist die Philosophie an der Macht. Verstehe ich von Hayek richtig, suchte er in seinem Spätwerk nach politischen und juristischen Steuerungsmechanismen, die der Kreativität der geldgetriebenen Ökonomie zugutekommen, ohne daß staatliche Interventionen zu para-sozialistischen Effekten führen. In diesem Kontext wird sein Satz plausibel, daß, wer nur etwas von Ökonomie verstehe, auch von Ökonomie nichts versteht. Tatsächlich ist Ökonomie —als Theorie der akquisitiven, possessiven und konsumptiven Leidenschaften - eine Humanwissenschaft, die in impliziten Philosophien gründet.

Aus meiner Sicht sind freilich nahezu sämtliche ökonomischen Philosophien falsch, auch jene von Hayeks, weil sie beim Menschen einseitig das Streben nach Aneignung und Selbstausdehnung betonen. Eine psychopolitisch realistische Theorie des Menschen müßte in diesem endlich wieder (anknüpfend an Platons psychologischen Intuitionen) den primären Widerstreit von Eros und Thymos hervorheben, das heißt das innere Ringen zwischen Habenwollen und Zu-Geben-Haben. Wer den wirklichen Menschen und seinen Ort im Stoffwechsel der Güter begreifen will, kommt nicht umhin, das Duell zwischen Besitzstreben und Großzügigkeit in Betracht zu ziehen. Der Kampf zwischen der Gier und der vornehmen Verausgabung vollzieht sich nicht bloß zwischen sozialen Gruppen; er bildet sich ab in der conditio humana jedes einzelnen. 
-Friedrich Hayek dijo que un buen economista no es sólo economista, y que a él le gustaba pensar que era algo más que sólo un economista. En los últimos años ha habido una predominancia de los economistas en la formulación de políticas públicas. En su desarrollo, ¿falta filosofía política?

- La pregunta acerca de si a nuestros sistemas de convivencia les falta filosofía, se contesta con un "no". Primero, no se ve un déficit de filosofía. Todos los actores esenciales en los escenarios estatales del mundo son Estados constitucionales. Las constituciones no son más que filosofías políticas congeladas, y no es raro que también antropologías políticas. Es lo que se muestra en los catálogos de derechos fundamentales y en el diseño de las instituciones, construidas en general sobre las ideas de la Ilustración sobre distribución de los poderes ejecutivo, legislativo y judicial. En el papel, es la filosofía en el poder. Si entiendo bien a von Hayek, en su obra tardía buscó mecanismos de conducción política y jurídica que vienen bien a la creatividad de la economía movida por el dinero, evitando que las intervenciones estatales conduzcan a efectos cuasi socialistas. En este contexto es plausible su dicho según el cual quien entienda sólo algo de economía, no entiende nada de economía. De hecho, la economía - como teoría de las pasiones adquisitivas, posesivas y consumistas - es una ciencia humana, que se funda en filosofías implícitas.

Desde mi perspectiva, son falsas casi todas las filosofías económicas, también la de F. von Hayek, porque acentúan unilateralmente las pulsiones de apropiación y de expansión de sí mismo. Una teoría psicopolítica realista del ser humano debiere finalmente levantar de nuevo, en vinculación con las intuiciones psicológicas de Platón, el conflicto primario de Eros y Thymos; esto es, la lucha interna entre querer tener y el sentido de orgullo y de vergüenza. Quien quiera concebir al hombre verdadero y su lugar en el intercambio de los bienes no llega a parte alguna si no toma en cuenta el duelo entre el impulso de poseer y la generosidad. La lucha entre la codicia y la ofrenda sensible no se materializa sólo entre grupos sociales; se construye a partir de la conditio humana de cada individuo. 
- Sie haben vorgeschlagen, dass Steuern freiwillig bezahlt werden sollen. Sie behaupten nämlich, dass die Regierungen mehr als die Hälfte der wirtschaftlichen Erfolge der Produktionschichten für sich verlangen, ohne dass die Betroffene die normale, angebrachte Reaktion zeigen: einen antifiskalischen Bürgerkrieg. Dies lässt sich nur mit den Schuldgefühlen erklären, die unsere Moralkultur in jeden Nicht-Armen einplanzt. Aber warum ist die Schuld die Erklärung und nicht eine rationale Auffassung à la Rawls? Warum glauben Sie, dass die Reichen freiwillig Steuer zahlen werden? Wie könnte sich der Staat organisieren und Pläne machen, wenn seine Einnahmen nur vom guten Willen der Bürger abhängen?

-Als ich so um 2010 die Idee vorbrachte, man soll die Steuern künftig nicht mehr als Schulden der Bürger beim Staat betrachten, sondern sie als freie Spenden der Zahler an den Fiskus ansehen, kam es in den deutschen Feuilletons, namentlich im linksliberalen und sozialdemokratischen Lager, zu einem Aufschrei der Wohlmeinenden: diese „neue soziale Kälte“, diese „,neoliberale Verrohung“, dieses „generationstypische Abgleiten eines alten 68ers zu neo-konservativen Positionen“. Nach wenigen Wochen der „Debatte“ war von meinen Überlegungen bloß noch ein zynisch grinsendes Gerippe übrig, das über den Trümmern des Sozialstaats tanzte. Diese Karikatur ging um die halbe Welt. Ich verkenne nicht, daß es eine Auszeichnung sein kann, Gegenstand von Karikaturen zu werden, außer man heißt Mohammed und legt die für Propheten kennzeichnende Überempfindlichkeit gegen die Ironie von Ungläubigen an den Tag. Dies ist bei mir, soweit ich sehe, nicht der Fall; doch zöge ich es vor, eine korrekte Paraphrase meiner Reflexionen zu lesen, bevor sie der Parodie zum Opfer fallen.

Der Grundgedanke meines Papiers über Die gebende Hand und die nehmende Seite lautete: Die einzige rechtssystematisch kohärente Begründung für die Erhebung von Steuern in Demokratien besteht in der Anerkennung des Steuerzahlers als eines Sponsors des Gemeinwesens. Die allenthalben vorherrschende Annahme, er sei in Wirklichkeit ein Schuldner des Staates, dem ganz recht geschieht, wenn er eine alljährliche Pfändung eines Teils seines Vermögens erleidet, erweist sich im Kontext meiner Überlegungen als eine moralische und politische Kalamität. In ihr manifestiert sich die psychopolitische Fehlkonstruktion der gesamten neueren Fiskalität: Diese hat vom Absolutismus und Spätfeu- 
-Usted propuso que el pago de impuestos sea voluntario. Señaló que los gobiernos reclaman al año para el fisco no menos de la mitad de todos los éxitos económicos de sus capas productivas, sin que los afectados recurran a la reacción más plausible a esta situación: la guerra civil anti-fiscal. Esto sólo se puede explicar por los sentimientos de culpa que nuestra cultura moral sabe inocular en todos los no pobres. ¿Por qué la culpa sería responsable y no una concepción racional de justicia a lo Rawls? ¿Por qué cree que los ricos voluntariamente pagarán impuestos? ¿Cómo podría el Estado planificarse y sostener sus políticas, si sus ingresos dependen sólo de la buena voluntad de los ciudadanos?

- Cuando en 2010 presenté la idea de que los impuestos no debían seguir siendo considerados como obligaciones de los ciudadanos para con el Estado, sino como aportes voluntarios de quienes los pagan al fisco, se dejó caer en las páginas culturales alemanas, en particular en el espacio liberal de izquierda y socialdemócrata, un griterío de los bien pensantes: esta "nueva insensibilidad social", este "neoliberalismo despiadado", este "desvío típicamente generacional de un tipo del 68 hacia posiciones neoconservadoras". Luego de unas pocas semanas de "debate", sólo quedó de mis reflexiones una irónica caricatura cínica, que bailaba sobre los escombros del Estado social. Esta caricatura dio vueltas por medio mundo. No desconozco que ser objeto de caricaturas pueda ser una distinción, a menos que uno se tenga por Mahoma y sufra esa hipersensibilidad frente a la ironía de los no creyentes tan característica de los profetas. No es ése mi caso, al menos así lo veo, pero preferiría leer una paráfrasis correcta de mis reflexiones antes de que ellas sean víctimas de la parodia.

El pensamiento principal de mi artículo periodístico "La revolución de la mano que da"9 decía que la única fundamentación sistemático-jurídica para la imposición de impuestos en democracias consiste en el reconocimiento del contribuyente como patrocinador de la comunidad. La percepción predominante por todas partes es entenderlo como un deudor del Estado, al que es justo privar cada año de una parte de su patrimonio. Esta concepción se muestra, en el contexto de mis reflexiones, como una

${ }^{9}$ Publicado originalmente en el periódico Frankfurter Allgemeine Zeitung, en el marco de la serie "Futuro del capitalismo", el 10 de junio de 2009. En castellano, está reproducido en Peter Sloterdijk, Fiscalidad voluntaria y responsabilidad ciudadana (Madrid: Siruela, 2014), 81-89. 
dalismus die Unterwerfung der Bürger unter den Staatszwang geerbt. $\mathrm{Zu}$ den Freiheiten der Demokratie muß unvermeidlich auch die Freiheit des Gebens für die Allgemeinheit gehören, wenn „Freiheit“ nicht ein Pseudonym für fiskalische Untertänigkeit sein soll. Die Bürgerschaft der Demokratie kann als Souverän erst dann glaubwürdig werden, wenn sie auch Souverän des Fiskus ist. Als solcher wäre sie als Geber von spontanen Beiträgen zur Gemeinwesen-Kasse anzusehen, entsprechend ihren Einsichten in deren Bedürfnisse; die Bürger dürften nicht länger als Dulder von Zwangsabgaben aufgefaßt und behandelt werden.

Wie man sieht, haben diese Überlegungen nichts mit dem Appell an den guten Willen der Reichen zu tun. Im übrigen kann man an der philanthropischen Kultur der USA ablesen, daß das Spenden zu Zwecken des Gemeinwohls keineswegs nur ein Hobby für Millionäre ist; es ist ein tief verankerter populärer Habitus. Von hier aus würde es eine zusätzliche Anstrengung der politischen Imagination kosten, um jede Art des Steuerzahlens offiziell als eine auto-philanthropische Geste der demokratischen Gesellschaft zu deklarieren. Dabei käme die Unterscheidung zum Tragen, die den größtmöglichen Unterschied bewirkt: Sind alle Steuerzahler als Geber anerkannt, so wäre jeder Beitrag zum Fiskus, vom kleinsten Betrag bis zur höchsten Summe, eine Leistung der Ehre, nicht des Zwangs, eine Geste der Freude, nicht ein Zugeständnis an die unvermeidliche Beraubung. Steuervermeidung käme dann der Ehrenvermeidung gleich. Was im Regime des Steuerzwangs eine zwar sträfliche, doch begreifliche Geste des Widerwillens darstellt, würde im Ökosystem der Ehre zur freiwilligen Schande. Ich meine also, es wäre ein anthropologisch informatives Experiment, zu erfahren, ob im Klima des Zwangs tatsächlich mehr Mittel in den Fiskus fließen als im Klima der ehrenvollen Empathie. Auf dem Feld des Zwangs wurde bereits so gut wie alles versucht. Auf das Experiment einer Fiskalität der Ehre wird man warten müssen.

Im übrigen beziehe ich mich mit dieser Reflexion auf die Anregungen von Marcel Mauss, der mit seiner Studie über Die Gabe, vor fast einhundert Jahren publiziert, noch immer die gegenwärtige Debatte überragt. Er hatte gezeigt, daß es die Gabe (le don) ist, die neben der Verwandtschaft das intensivste soziale Band stiftet. Das Rätsel der Gabe besteht darin, daß sie zweipolig wirkt: zum einen ist sie ein Akt der Spontaneität, zum anderen erzeugt sie die Pflicht zur Gegengabe. In ihr fallen Pflicht und Freiheit in eins. Interpretiert man von Mauss her die Steuern 
calamidad política y moral. En ella se manifiesta la falla constructiva psicopolítica de toda la política fiscal moderna, que ha heredado del absolutismo y del feudalismo tardío la sumisión de los ciudadanos al poder estatal. A las libertades democráticas también pertenece inevitablemente la libertad del dar para la comunidad, si por "libertad" no entendemos un seudónimo de sometimiento. La ciudadanía en una democracia sólo puede ser creíble si también es soberana respecto del fisco. Como tal, las personas serían tratadas como dadores de contribuciones espontáneas a la caja común, en correspondencia con sus percepciones acerca de las necesidades comunes; los ciudadanos no pueden seguir siendo concebidos ni tratados como sujetos sometidos a aportes forzosos.

Como se ve, estas reflexiones nada tienen que ver con una invocación a la buena voluntad de los ricos. Por lo demás, puede verse en la cultura filantrópica norteamericana que los aportes para fines de bien común en ningún caso son una afición de millonarios; se trata de un hábito popular de arraigo profundo. A partir de todo esto, sería una exigencia adicional a la imaginación política declarar oficialmente que los impuestos de todo tipo resulten de actos auto-filantrópicos en la sociedad democrática. Entonces operaría una diferencia mayor con la sustracción: si todos los contribuyentes son reconocidos como dadores, cada contribución al fisco, desde la suma más pequeña a la más grande, sería considerada como un acto de honor, no de imposición, un gesto de alegría, no de sometimiento a una sustracción inevitable. La evasión tributaria pasaría a igualarse con el deshonor. Lo que en el régimen de imposición forzosa, con su consecuencia penal, es un evidente gesto de aversión, pasaría a ser un ecosistema del honor y la evasión, una vergüenza voluntaria. Creo que así introduciríamos un experimento antropológicamente informativo acerca de si de un clima de fuerza efectivamente fluyen más recursos al fisco que de uno de empatía honorable. Se ha intentado hacer prácticamente todo desde la perspectiva de la fuerza. Tendremos que esperar al experimento de la fiscalidad del honor.

Por lo demás, con esta reflexión me acerco a las recomendaciones de Marcel Mauss, cuyo ensayo sobre El don, publicado hace casi cien años, todavía supera el debate actual. Él mostró que el dar - le don-, junto al parentesco, es fundamento del más intenso vínculo social. La paradoja del dar consiste en que opera de modo bipolar: por un lado es un acto de espontaneidad y por otro crea el deber de reciprocidad. En él 
in neuem Licht, so könnte sich zeigen, daß der Staat nicht notwendigerweise etwas verliert, wenn er den Bürgern die Fähigkeit zutraut, ihn mit den Mitteln auszustatten, die er zu seinem Funktionieren braucht.

-Was meinen Sie von den populistischen und nationalistischen Führern, die einen großen Erfolg in den letzten Jahren gehabt haben? Was ist mit den gemäßtigeren Politikern passiert? Sind sie schon verschwunden, oder sind sie vom Aussterben bedroht, oder machen sie nur gerade eine schwere Zeit durch? Beispiele dafür sind Trump in den USA und Jair Bolsonaro in Brasilien.

-Der Erfolg neo-nationaler Partei-Bewegungen in vielen Gegenden der Welt ist eine aus sozialdynamischer Sicht völlig logische Antwort auf das Geschehen, das man seit einigen Jahrzehnten „Globalisierung“ nennt. Daß die Mehrzahl der Soziologen und Politologen im Westen hierauf mit Staunen und Empörung antworten, legt die Einseitigkeit ihrer Bildung offen. Die meisten von ihnen haben offenbar nie etwas vom dritten Newtonschen Gesetz gehört, welches lautet: Aktion ist gleich Reaktion. Wo man davon Kenntnis genommen hat, versucht man zu erklären, warum es hier nicht gelten soll. Man reklamiert für die politische Sphäre eine Sonderphysik, der zufolge die Aktion immer Recht hat und die Reaktion unrecht. Die erste ist innovativ, die zweite gehorcht den Trägheitsgesetzen. Im 19. Jahrhundert war reaktionär, wer den Fortbestand von Verhältnissen wünschte, die auf dem Vorrang von Monarchen, Aristokraten und Kolonialherren beruhten. Man wird nicht abstreiten, dass die anti-reaktionäre Seite diesbezüglich starke Gründe für ihr Plädoyer in Anspruch nehmen konnte.

Das 20. Jahrhundert war vom Tumult der revolutionären Reaktionen dominiert - an erster Stelle der Anti-Liberalismus (katholisch, faschistisch, kommunistisch) und der Anti-Kolonialismus. Am Beginn des 21. Jahrhunderts antwortet die „Reaktion“ auf den Trend zur Auflösung der Volksgemeinschaften durch transnationale Eliten, zur Auflösung der jüngst erfundenen Nationen durch postnationale Bündnisse, zur Auflösung der organisierten Nationalproletariate durch entgrenzte Arbeitsmärkte und zur Auflösung der Völker durch sich vermischende Gen-Pools.

Das Originelle der heutigen Situation zeigt sich darin, daß man - anders als in den zwanziger und dreißiger Jahren des 20. Jahrhunderts - die „reaktionäre“ Qualität auch der linksradikalen Positionen 
se funden en uno el deber y la libertad. Si se interpretan los impuestos bajo una nueva luz, desde Mauss, puede mostrarse que el Estado no necesariamente pierde si confía a los ciudadanos la capacidad de proveerlo con los medios que requiere para su funcionamiento.

- ¿Qué opina de los líderes populistas, nacionalistas que han tenido un éxito importante en los últimos años? ¿Qué pasa con el centro politico? ¿Desapareció, está en vías de disolución o sólo pasa por un mal período? Donald Trump es un ejemplo; Jair Bolsonaro, en Brasil, otro.

-Desde una perspectiva sociodinámica, el éxito de movimientos o partidos neo-nacionalistas en muchos lugares del mundo es una respuesta completamente lógica al fenómeno que desde hace algunos decenios se llama "globalización”. Que la mayoría de los sociólogos y politólogos de Occidente respondan a ella con asombro y escándalo deja al descubierto la unilateralidad de su formación. La mayoría de ellos obviamente nunca han oído de la tercera ley de Newton: acción es igual a reacción. Sólo si se toma conocimiento de ello, se puede intentar una explicación de por qué no debe regir también en la política. Se reclama para la esfera política una física especial, donde la acción siempre está en lo correcto y la reacción en lo incorrecto. La primera es innovativa y la segunda pertenece a las leyes de la inmutabilidad. En el siglo XIX era reaccionario quien deseaba la permanencia de relaciones basabas en el predominio de monarcas, aristócratas y señores coloniales. No se puede negar que el sector antireaccionario podría hoy invocar fuertes razones para su manifiesto.

El siglo XX estuvo dominado por el tumulto de las reacciones revolucionarias; en primer lugar del antiliberalismo (católico, fascista y comunista) y del anticolonialismo. A comienzos del siglo XXI, la "reacción" responde a una tendencia de la disolución de las comunidades nacionales por élites transnacionales, a la sustitución de naciones recién reencontradas por asociaciones trasnacionales, a la disgregación del proletariado nacional organizado por mercados laborales sin fronteras y a la disolución de los pueblos por gene-pools que se entremezclan.

Lo original de la situación actual se muestra en que, a diferencia de los años veinte y treinta del siglo XX, la característica "reaccionaria" se reconoce a simple vista en las posiciones radicales de izquierda, 
mit freiem Auge erkennt, um von den rechtsextremen zu schweigen. Es wird immer schwieriger, mit den Reflexen des 20. Jahrhunderts die Gegebenheit des 21. zu interpretieren. Ironischerweise verlangt die politische Vernunft jetzt Mitgefühl mit den „Reaktionären“. Man darf ihnen aber nicht erlauben, die Mitte zu zerstören, von der aus allein gestaltende Politik möglich ist. Dazu gehört ein Denken in größeren Zeitbögen. Pathologische Figuren wie Trump, Bolsonaro, Duterte, Erdogan, Putin und andere werden ohne Zweifel enorme Schäden am Geist ihrer politischen Gemeinwesen anrichten. Unter dem Aspekt größerer Erzählungen bilden sie nicht mehr als vergängliche Kapitel.

—Was denken Sie über die Globalisierung? Wie sehen Sie den Schutz der lokalen Industrie und die Migrationsprozesse?

-Man sollte als erstes einsehen, daß die sogenannte Globalisierung in erster Linie ein Ereignis in der Wahrheitsgeschichte ist, verbunden mit der Geschichte der Kosmologie und der Seefahrt. In ihr geht es um den Beweis für die Globus-Gestalt der Erde. Diese wurde von griechischen Geometer-Philosophen zuerst um das Jahr 500 v. Chr. in der Nachfolge des Pythagoras dargestellt; sie wurde von europäischen Seefahrern wie Kolumbus, Vasco da Gama und Magellan mit nautischen Mitteln bewiesen und von Physikern wie Kopernikus und Kepler wissenschaftlich expliziert; zurzeit wird sie durch die International Space Station alle neunzig Minuten bestätigt. $\mathrm{Da}$ die Erde eine planetarische Monade ist, eine quasi-sphärische Singularität, von zahllosen Lebensformen bevölkert, das ist eine Erkenntnis, deren Belastbarkeit beweist, daß die Empirie der Mathematik ebenbürtig werden kann.

Es waren europäische Kosmographen und Seefahrer, die den Völkern der ganzen Welt diese Erkenntnis aufgezwungen haben. Mit Eurozentrismus hat dies nichts zu tun. Die Erde-Wahrheit gilt für alle, die die Erde bewohnen, gleichgültig, ob sie sie aus eigener Kraft entdeckt hätten oder nicht. Gegen Wahrheit ist der Protektionismus wirkungslos, überdies auf Dauer ohne Sinn. Daß nun sehr viele von denen, die von Europäern entdeckt und zeitweilig unterdrückt wurden, nach Europa streben oder nach der europiden Ex-Kolonie USA, das beweist, wie sehr sie von der geographischen Aufklärung durch Europäer und Amerikaner durchdrungen sind. Migrationen sind zweideutig: Sie zeigen, daß Menschen Gründe zur Flucht vom Ausgangsort haben; ebenso be- 
$\mathrm{y}$ ni hablar de los extremismos de derecha. Con los reflejos del siglo $\mathrm{XX}$, es cada vez más difícil interpretar las realidades del siglo XXI. Irónicamente, la racionalidad política exige compasión con los "reaccionarios". Pero es claro que no se les puede permitir destruir el centro, porque sólo desde allí es posible una política constructiva. A esto lleva un pensamiento en marcos de tiempo más extensos. Figuras patológicas como Trump, Bolsonaro, Duterte, Erdogan, Putin y otros producirán, sin duda, enormes daños al espíritu de sus comunidades políticas. Desde la perspectiva de los grandes relatos, ellos no son más que capítulos transitorios.

—QQué percepción tiene de la globalización? ¿Cómo ve la protección de las industrias locales y los procesos migratorios?

-Debiese, ante todo, comprenderse que la llamada globalización es en primera línea un acontecimiento en la historia de la verdad, relacionada con la historia de la cosmología y de la navegación. En ella va envuelta la prueba de la configuración global de la Tierra. Ella fue representada ya alrededor del 500 antes de Cristo por los filósofos-geómetras herederos de Pitágoras, y fue probada con medios náuticos por marinos europeos como Colón, Vasco de Gama y Magallanes, y demostrada científicamente por físicos como Copérnico y Kepler. En nuestro tiempo es confirmada cada noventa minutos por la International Space Station. Que la Tierra es una mónada planetaria, una singularidad cuasi esférica, habitada por incontables formas de vida, todo eso es un conocimiento cuya resiliencia muestra que el empirismo de las matemáticas puede llegar a ser igual que el de las otras ciencias.

Los cosmógrafos y navegantes europeos fueron quienes impusieron este conocimiento a los pueblos de todo el mundo. Eso nada tiene que ver con eurocentrismo. La "verdad de la Tierra" vale para todos los habitantes de la Tierra, con independencia de si la alcanzaron con sus propios medios. Contra la verdad es ineficaz el proteccionismo. Más aún, a la larga es un sinsentido. Que ahora muchos de aquéllos que fueron descubiertos y por un tiempo sometidos por europeos quieran llegar a Europa o a la ex colonia europea, Estados Unidos de América, muestra cómo están permeados por la ilustración geográfica europea y norteamericana. Las migraciones son ambiguas: muestran, por un lado, que hay gente que quiere huir de su lugar de origen; también muestran que 
weisen sie, dass es Attraktoren gibt, die die Fluchtbewegung zu einem Zielort lenken. Beide Beobachtungen bestätigen das Diktum: Ubi bene ibi patria.

-Das Oxford Englisch-Wörterbuch hat das Wort post-truth (, postfaktisch”) zum Wort des Jahres 2016 gekürt. Glauben Sie, dieses Phänomen hat etwas zu tun mit dem Vorrang des Scheins, der von den sozialen Netzwerken gefördert wird? Hat die Wahrheit einen Platz in einer virtuellen Welt?

-Ein Eintrag wie post-truth illustriert, daß die Redakteure des seriösesten Wörterbuchs der Welt gegen Bluff nicht immun sind. Es kann keine Situation ,nach der Wahrheit“ geben, weder logisch noch historisch. Daß Donald Trump am 20. Januar 2017 vor der Westfront des Kapitols zu Washington auf das Amt des Präsidenten der Vereinigten Staaten vereidigt wurde, bleibt eine Tatsachenwahrheit bis zum Ende der Zeiten. Daß er seither im Durchschnitt acht Mal am Tag vor Zeugen irrt und lügt, wird in den Annalen des Amts für immer festgehalten. Was man tatsächlich weltweit beobachtet, ist eine galoppierende Inflation erfundener Nachrichten und gefälschter Bilder. Erfahrung beweist aber, daß man auch nach größten Inflationen zu überschaubaren Werten zurückkehrt. Wer unkritisch von post-truth spricht, verrät die Neigung zum Einknicken vor aufgetakelten Slogans.

Was man seit gut einem Jahrzehnt tatsächlich beobachtet, ist die maßlose Vermehrung von Privatbotschaften durch die sogenannten sozialen -wahrscheinlich eher: asozialen- Medien. Bei diesen sollen Besucherzahlen die Bedeutsamkeit einer Publikation beweisen. Konsensus beweist aber nichts. Würden sieben Milliarden Follower die Botschaft bestätigen, die Erde sei eine Scheibe, würde dennoch der eine die Wahrheit sagen, der ihre Kugelgestalt feststellt. Die globale Vernetzung parasitiert die Tatsache, daß sich alle Netze über die eine Erde ausspannen. Die Trägerin aller Konstrukte ist selbst kein Konstrukt.

—In einem Interview mit Le Point sagen Sie, dass das „Selfie” eine neue autobiographische Gattung sei, in der eine Notwendigkeit der Verbreitung und Fixierung des narzisstischen Wunsches auftaucht. Sie sagen zudem, der "Idiot” sei besessen von seinem Selbstbild. Die neuen Technologien fordern unser Verständnis der Wirklichkeit heraus. 
hay puntos de atracción que orientan hacia un punto de destino. Ambas observaciones confirman el proverbio: ubi bene, ibi patria. ${ }^{10}$

-El diccionario inglés Oxford declaró el término "posverdad" como la palabra internacional del año 2016. ¿Cree que este fenómeno está vinculado con la preeminencia de la apariencia que promueven las redes sociales? En un mundo virtual, ¿qué lugar le cabe a la verdad?

-Una entrada como posverdad ilustra que los redactores del diccionario más serio del mundo no son inmunes a la patraña. No puede haber una situación "después de la verdad", tanto lógica como históricamente. Que Donald Trump haya jurado como Presidente de los Estados Unidos el 20 de enero de 2017 delante del Capitolio, es una verdad de hecho hasta el fin de los tiempos. Que él desde entonces yerre o mienta en promedio ocho veces al día, permanecerá para siempre en los anales del cargo de la presidencia. Lo que en verdad se observa a lo ancho del mundo es una inflación galopante de noticias inventadas y de imágenes falsificadas. La experiencia muestra, sin embargo, que luego de las más grandes inflaciones se regresa a valores más acotados. Quien habla de manera acrítica de la posverdad, muestra una tendencia a arrodillarse ante eslóganes pretenciosos.

Lo que de hecho se observa desde hace una década es la desmedida multiplicación de comunicaciones privadas por las llamadas redes sociales, que más bien son asociales. La importancia de una publicación se mide por el número de visitantes. Pero el consenso no prueba nada. Si siete mil millones de seguidores confirmaran la noticia de que la Tierra es un disco, sería un despropósito, pero el único que dijera la verdad confirmaría que es una esfera. En la red global parasita la evidencia de que todas las redes se extienden sobre el planeta Tierra. La portadora de todos estos constructos no es en sí misma más que un constructo.

-En una entrevista con Le Point usted menciona que la "selfie" es el nuevo género autobiográfico, como si fuese necesario divulgar y fijar de forma permanente el deseo narcisístico. También dice que hoy el "idiota" está obsesionado con la imagen de sí que brinda a los otros. ${ }^{11}$ Las nuevas tecnologías de la comunicación están desafiando

${ }^{10}$ Donde esté el bien, ahí está mi patria.

${ }^{11}$ Christophe Ono-Dit-Biot, "Les charlatans vont-ils nous ruiner?", Le Point, 31 de mayo de 2018. 
Plötzlich sieht es so aus, als ob unser Leben auf Facebook, Instagram, Twitter wichtiger als unser reales Leben wäre. Glauben Sie, dass der Schein die Wirklichkeit übertreffen wird? Benötigt man eine neue Ontologie oder handelt es sich einfach um eine neue Form der Schenkung des Seins?

-Das Leben als Philosoph hat viele Nachteile: Zum Beispiel muß man ständig mitansehen, wie andere Leute sich mit Illusionen vollfressen, während man selber auf Diät lebt. Andererseits hat man gelegentlich Vorteile: Wenn Amateure über Schein und Sein reden oder von der Deklassierung humaner Subjekte durch intelligente Maschinen phantasieren, weiß man dank des Metiers im Voraus ungefähr, bis wohin dergleichen führt. Man erinnert sich an das Goldene Jahrhundert Spaniens, das virtuos über wahre Gesichter und Masken diskutierte oder die frühe deutsche Romantik, die über den ontologischen Status von Fiktionen schon alles wußte. Wer eine größere Bibliothek hat, kennt auch Jorge Luis Borges, für den alles, was ist, aus ironischen Selfies des Absoluten besteht.

- In diesem Jahr gedenkt man in Chile des Putsches vom 11. September 1973 und des Anfangs der Diktatur, die bis 1990 dauerte, als das Plebiszit die Rückkehr der Demokratie ermöglicht hat. Dieser Prozess ist eine Wunde, die die Chilenen immer noch trennt. Am Anfang der 80er Jahre hat eine bis heute andauernde Liberalisierung der Wirtschaft begonnen. Wie sehen Sie im Großen und Ganzen die chilenische Situation?

-Für einen Europäer ist Chile an erster Stelle eines: fast unvorstellbar weit entfernt. Man kann auf dem Planeten kaum noch weiter wegfahren. Danach kommen unsereinem die Namen Allende und Pinochet ins Gedächtnis. Mit einem Mal rückt uns das ferne Land sehr nahe. Wir spüren, Chile gehört zur Familie der tragischen Nationen. Man hat ein gemeinsames Thema: Modernisierung, Verbrechen und ungleichmäßige Entwicklung. Ich hatte vor vielen Jahren einen Schüler, der unter Allende als Polizist gedient hatte und fliehen mußte. Er hatte Anspruch auf Asyl, er studierte Deutsch. Von ihm habe ich den Text von Guantanamera gelernt: „Mein Vers ist von einem hellen Grün und von brennendem Rot; mein Vers ist ein verletztes Wild, das Schutz sucht in den Bergen." Später erreichte Allendes Großnichte Isabel mit ihren Ro- 
nuestra comprensión de la realidad. De pronto, pareciera ser que lo que nos sucede en los portales virtuales como Facebook, Instagram, Twitter es más importante que lo que nos pasa en la vida real. ¿Cree que la apariencia logrará superar la realidad? ¿Se requiere una nueva ontología o es simplemente una nueva forma de donación del ser?

- La vida como filósofo tiene muchas desventajas. Por ejemplo, se es permanentemente testigo de cómo la gente se engolosina con ilusiones, mientras uno mismo vive a dieta. Pero también a veces tiene ventajas: cuando aficionados hablan de "parecer" y "ser", o cuando se fantasea sobre la degradación de los sujetos humanos por máquinas inteligentes, se sabe por adelantado gracias al oficio hacia dónde conduce todo eso. Se recuerda el siglo de oro español, cuando se discutió con virtuosismo sobre rostros verdaderos y máscaras; o el romanticismo alemán temprano, que sabía todo acerca del estatus ontológico de las ficciones. Quien tiene una gran biblioteca, conoce también a Jorge Luis Borges, para quien todo lo que es se compone de selfies irónicas del absoluto.

-Este año ${ }^{12}$ se cumplieron 45 años desde el golpe de estado del 11 de septiembre de 1973 en Chile y el inicio de la dictadura hasta el plebiscito que permitió el retorno a la democracia en 1990. Este proceso es una herida que todavía divide a los chilenos. A principios de los años ochenta se inició una liberalización económica en Chile que se ha mantenido hasta estos días. A grandes rasgos, ¿cómo ve la situación en Chile?

-Para un europeo, Chile es ante todo casi inimaginablemente lejano. Apenas se puede ir más lejos en el planeta. Después nos vienen a la mente los nombres de Allende y Pinochet. De una vez se nos acerca mucho el lejano país. Sentimos que Chile pertenece a la familia de las naciones trágicas. Se tiene un tema común: modernización, delitos y desarrollo desigual. Hace muchos años tuve un alumno que había sido policía en el gobierno de Allende y debió huir. Tenía la pretensión de obtener asilo y estudió alemán. Gracias a él aprendí el texto de "Guantanamera": "Mi verso es de un verde claro y de un carmín encendido. Mi verso es un ciervo herido que busca amparo en el monte". Más tarde

\footnotetext{
${ }^{12}$ Recordemos que esta conversación se llevó adelante en 2018.
} 
manen hohe Auflagen in dem Verlag, in dem auch ich publiziere. War es die nemesis divina? War es ein Teil der chilenischen Regeneration? Sie selbst schien mit der schlimmen Geschichte ihren Frieden gemacht zu haben, als sie 2010 den nationalen Literaturpreis entgegennahm.

—Wie sehen Sie die Krise der katholischen Kirche, dieses großen Verwalters der Wut? Glauben Sie, dass zumindest im Abendland die Wissenschaft diese Rolle der Religion übernehmen wird, wie es Nietzsche vorausgesagt hat?

-Die katholische Kirche existiert mindestens seit 1789 in der Krise. Sie hat sich auf die Kunst des Überlebens spezialisiert, indem sie zuerst die Nicht-Anpassung erprobte, dann die Anpassung. Es gibt keinen Grund, warum das nicht noch tausend Jahre weiter gehen sollte. Der „Wille zum Glauben“, von dem William James 1896 sprach, durchläuft historische Konjunkturen, im langfristigen Mittel bleiben seine Werte konstant. Als Verwalterin des Zorns spielt die Kirche keine Rolle mehr; Johannes Paul II bemerkte gelegentlich: „Hoffen wir, daß die Hölle leer sei“. Doch nicht die Wissenschaft löst den Katholizismus als Zorn-Verwalterin $a b$, sondern der Islam, solange er das Jenseits mit seinen beiden Abteilungen als feste Größen verteidigt.

-Der Mensch versucht heute - und wahrscheinlich wird er es noch lange versuchen - sein Leben zu verlängern. Die Experten behaupten, dass wir bald 150 oder 200 Jahren leben werden. Was denken Sie von alledem? Würden Sie gerne so viele Jahren leben? Experten behaupten sogar, der Mensch werde die Unsterblichkeit erreichen. Heidegger sagt, dass der Tod unsere Existenz vollkommen prägt. Würden wir noch Menschen sein, wenn wir unsterblich werden? Welche ethischen Konsequenzen sehen Sie dabei?

-Die Gefahr, daß Menschen je unsterblich würden, außer im Andenken späterer Generationen, besteht nicht wirklich. Die Aussicht auf 150 oder 200 Jahre Dasein im selben Körper ist schlimm genug. Man würde spätestens ab sechzig völlig neurotisch, weil man sich keine kleine Blessur, keine Grippe, keinen Kuß, keinen Handschlag mit einem Nachbarn mehr leisten könnte, immer im Gedanken an die hundert Lebensjahre, die man durch den geringsten Fehler aufs Spiel setzt. Man wäre dazu verurteilt, sein Leben ab achtzig in einem biologischen Hochsicherheitstrakt zu verbringen, als Gefangener der eigenen Langlebigkeit. 
encontré que Isabel, sobrina nieta de Allende, lograba grandes tirajes para sus novelas en la misma editorial donde yo publicaba. ¿Qué es la némesis divina? ¿Era una parte de la regeneración de Chile? Ella misma parece haber hecho la paz con la historia doliente, en particular cuando en 2010 recibió el Premio Nacional de Literatura.

- ¿Cómo ve la crisis de la Iglesia Católica, ese gran administrador de la ira? ¿Cree que la ciencia reemplazará a la religión en este rol, al menos en Occidente, como lo adelantó Nietzsche?

- La Iglesia Católica está en crisis al menos desde 1789. Se ha especializado en el arte de la sobrevivencia, en tanto primero probó la no adaptación y, luego, la adaptación. No hay razón para que eso no perdure otros mil años. La "voluntad de creer", de la que hablaba William James en 1896, atraviesa coyunturas históricas y en el largo plazo sus valores permanecen constantes. La Iglesia ya no juega ningún rol como administradora de la ira. Juan Pablo II remarcaba ocasionalmente: "Esperemos que el infierno esté vacío". Pero no ha sido la ciencia la que ha reemplazado a la Iglesia como administradora de la ira, sino el Islam, en la medida en que logre defender el más allá.

-El ser humano busca -y probablemente seguirá buscandoextender la vida por más años. Los especialistas dicen que pronto viviremos 150 años e incluso 200. ¿Qué le parece todo esto? ¿Le gustaría vivir esa cantidad de años? Es más, algunos especialistas dicen que en pocos años más podremos alcanzar la inmortalidad. Heidegger dice que la muerte determina nuestra existencia completa. ¿Dejaríamos de ser hombres si alcanzáramos la inmortalidad? ¿Qué consecuencias éticas avizora?

- No existe en verdad el riesgo de que los hombres sean alguna vez inmortales, más allá del recuerdo de las generaciones posteriores. La expectativa de vivir 150 o 200 años en el mismo cuerpo es suficientemente terrible. Antes de los sesenta años el ser humano se volverá completamente neurótico, porque no podría permitirse ni una pequeña herida, ninguna gripe, beso o apretón de manos con el vecino, ya que siempre estaría pensando en los cien años de vida que se ponen en juego con el más mínimo error. Se estaría condenado, desde los ochenta, a pasar la vida en un centro biológico con estándares de alta seguridad, como preso de su propia longevidad. 
Fast alles Böse folgt bekanntlich aus dem verwilderten Willen zur Selbsterhaltung. Der entspringt der Unfähigkeit einzusehen, wann es genug ist. Würden wir in der Mehrheit über 150 Jahre alt, die Greisenbosheit ohne Grenzen würde die Welt in endlose Kriege stürzen, jenseits von Hobbes und Harmageddon. Also sollte das Leben weniger auf Verlängerung ausgehen als auf Vertiefung. $E P$ 
Como se sabe, casi todo mal se sigue de la feroz voluntad de autoconservación. Nace de la incapacidad de comprender cuándo ya es suficiente. Si la mayoría de nosotros viviera sobre 150 años, la maldad sin fronteras de los ancianos haría caer al mundo en innumerables guerras, más allá de Hobbes y el Armagedón. Por eso, la vida debiera orientarse menos hacia su prolongación y más hacia su profundidad. EP 